\title{
Association Between Life-style, Metabolic Syndrome and Lower Urinary Tract Symptoms and Its Impact on Quality of Life in Men $\geq 40$ years
}

\section{Ji Bong Jeong}

Seoul National University Boramae Medical Center

Jung Hoon Lee

Seoul National University Boramae Medical Center Min Soo Choo

Seoul National University Boramae Medical Center

\section{Dong-Won Ahn}

Seoul National University Boramae Medical Center

\section{Su Hwan Kim}

Seoul National University Boramae Medical Center

\section{Dong Seok Lee}

Seoul National University Boramae Medical Center

\section{Min Chul Cho}

Seoul National University Boramae Medical Center

Hwancheol Son

Seoul National University Boramae Medical Center

Hyeon Jeong

Seoul National University Boramae Medical Center

\section{Sangjun Yoo ( $\nabla$ ebend@naver.com )}

Seoul National University Boramae Medical Center

\section{Research Article}

Keywords: LUTS, multivariable analysis, age, amount of life-long smoking, marital status

Posted Date: September 17th, 2021

DOI: https://doi.org/10.21203/rs.3.rs-885578/v1

License: (a) (i) This work is licensed under a Creative Commons Attribution 4.0 International License. Read Full License 


\section{Abstract}

Purpose: We aimed to assess the relationship between lifestyle-related variables, metabolic syndrome, and lower urinary tract symptoms (LUTS) in men $\geq 40 y e a r s$. We also assessed the impact of these variables on quality of life.

Materials and methods: From 2014 to 2020, 5,355 men who underwent health check-ups with I-PSS questionnaires at our institute were included in the analysis. The impact of LUTS on sleep disorders and moderate to severe degrees of stress were assessed. Multivariate analysis was performed to determine the variables associated with LUTS and prostate volume.

Results: Moderate and severe LUTS were present in 1,317 (24.6\%) and 211 (3.9\%) men, respectively. Moderate and severe LUTS were significantly associated with the presence of sleep disorders and stress. On multivariable analysis, age, amount of life-long smoking, marital status, income, job, and decreased HDL-cholesterol were associated with the presence of moderate to severe LUTS. Central obesity and decreased HDL-cholesterol levels were also significantly associated with prostate volume, in addition to age.

Conclusions: In men $\geq 40 y e a r s$, stable socioeconomic status is negatively associated with moderate to severe LUTS, which worsens sleep quality and stress level. In addition, quitting smoking and maintaining HDLcholesterol over $40 \mathrm{mg} / \mathrm{dL}$ might be effective for preventing moderate to severe LUTS.

\section{Introduction}

Recently, as life expectancy has increased, interest in the quality of life (QoL) in elderly individuals is rapidly increasing. In elderly men, lower urinary symptoms (LUTS) were reported to significantly worsen QoL ${ }^{1,2}$. However, currently, no clear strategies to prevent the development of LUTS have been developed, despite more than $40 \%$ of men suffering from at least one LUTS ${ }^{3}$. When we consider the medical costs for relieving LUTS in elderly men ${ }^{4}$ and its impact on individual QoL, the development of strategies to prevent LUTS in men is urgently needed.

Maintaining a positive health status is thought to be important for improving QoL, and preventing metabolic syndrome (MetS) is one of the most important concepts for maintaining a positive health status, especially when a person gets older ${ }^{5-7}$. Traditionally, MetS has been regarded as an important risk factor for cardiovascular or cerebrovascular events ${ }^{5}$. However, recently, the relationship between MetS and other chronic diseases has been increasingly reported ${ }^{6,7}$, and LUTS and benign prostatic hyperplasia (BPH) in men have also been reported to be associated with MetS and its components ${ }^{8}$.

In our previous studies, we identified that MetS and its components, especially decreased high-density lipoprotein $(\mathrm{HDL})$ cholesterol, are related to the presence of prostatic disease, including BPH and prostate cancer, using a large national health insurance database cohort ${ }^{9,10}$. However, because the severity of LUTS has not been routinely measured as a health check-up in the normal population, there are only a few studies that address the impact of MetS and its components on the severity of LUTS, and these studies did not show consistent results 11-14. This might be due to the complex correlation between lifestyle variables, MetS, and LUTS; to elucidate the real impacts of MetS and lifestyle factors on LUTS, thorough analysis using a large database with detailed information is needed. 
In our institute, the International Prostate Symptom Score (I-PSS) questionnaires were routinely administered in men who visited the health check-up center. In this study, we aimed to assess the relationship between MetS/lifestyle-related variables and LUTS using these databases, in addition to its impact on QoL. We evaluated the impacts of LUTS on sleep quality and stress to address the effects of improving LUTS on QoL. In addition, we assessed the association between the severity of LUTS and metabolic components and lifestyle-related variables to elucidate the prevention strategies for moderate to severe LUTS to improve QoL by lifestyle modification. We also assessed the impact of these variables on prostate volume to demonstrate the possible reasons for moderate to severe LUTS in these men.

\section{Methods}

\section{Study population}

From 2014 to 2020, men who underwent health check-ups at our institute were eligible for the current study. Among these, 10,353 men who completed the I-PSS questionnaire were initially selected for the study. Then, 3,477 duplicated cases were excluded from the analysis. In addition, 1,263 men aged $<40$ years and 165 men who did not undergo body measurements were excluded. After excluding 54 men who were taking medications for BPH, 40 men with cerebrovascular disease, and 26 men with chronic kidney disease, 5,355 men were finally included in the analysis. The current study was approved by the institutional review board of the Boramae Medical Center and the informed consent has been waived by the institutional review board of the Boramae Medical Center. In addition, all methods were performed in accordance with the relevant guidelines and regulations.

\section{Health check-up}

Men who underwent health check-ups at our institute routinely performed the Korean version of I-PSS ${ }^{22}$, Pittsburgh sleep quality index (PSQI) questionnaires ${ }^{23}$, and modified Korean-translated brief encounter psychosocial instrument (BEPSI-K) ${ }^{24}$. Demographic characteristics, including age, body weight, and height, were measured, and social history and lifestyle-related factors, such as smoking, drinking, marital status, job, and income, were collected before medical check-up. We divided the age group into four categories ( $\geq 40$ and $<50$ vs. $\geq 50$ and $<60$ vs. $\geq 60$ and $<70$ vs. $\geq 70$ ). We divided the job into three groups (office worker vs. others vs. unknown), marital status into three groups (yes vs. no (including single, divorced, and separated) vs. unknown), and monthly income into three groups ( $\geq \$ 2684$ vs. $<$ \$2684 vs. unknown). In addition, smoking status was divided into two groups (current smoker or not), while drinking status was divided into four categories according to weekly alcohol consumption ( $0 \mathrm{~g}$ vs. $<100 \mathrm{~g}$ vs. $\geq 100 \mathrm{~g}$ vs. unknown). The metabolic equivalent of task (MET) was calculated and log-transformed due to its deviated distribution. Using the NCEP ATP III definition, MetS was defined as the presence of any of the three components among the five metabolic components ${ }^{25}$. Using PSQI questionnaires, we determined the presence of sleep disorders as $\geq 5$ scores ${ }^{26}$. Using BEPSI-K questionnaires ${ }^{27}$, the presence of moderate to severe stress was defined as a mean score of $\geq 1.8^{28}$. Among 5,355 men, 827 patients underwent transrectal ultrasound to measure prostate volume, and the impacts of metabolic components and lifestyle-related variables on prostate volume were analyzed using these men.

\section{Statistical analysis}


We divided the participants into three groups according to their I-PSS score (1-7: none to mild vs. 8-19: moderate vs. 20-35: severe). Characteristics are presented as mean \pm SD for continuous variables and frequency with proportion for categorical variables. Continuous and categorical variables were compared using the ANOVA test and chi-square test, respectively. We performed univariate and multivariate analyses to reveal the impact of LUTS on sleep disorders and stress. Because both moderate and severe LUTS showed significant impacts on worsening sleep quality and stress status, we determined the variables associated with the presence of moderate to severe LUTS. Patients were subdivided according to age groups, and the proportion of men with moderate to severe LUTS according to lifestyle-related variables, MetS, and metabolic components were calculated and compared. Univariate and multivariate analyses were performed to determine the variables associated with the presence of moderate-to-severe LUTS. Variables with $p<0.2$ in the univariate analysis were included for multivariable analysis using backward elimination. Because unknown categories in marital status, income, and job showed similar odds ratios compared with others, $<\$ 2,684$, and others, respectively, marital status, income, and job were re-categorized into two groups for the linear regression analysis. The variables associated with total I-PSS, voiding, and storage sub-scores were determined using univariate and multivariate linear regression analyses. In addition, variables associated with prostate volume were determined using univariate and multivariate linear regression analyses. In this study, $p<0.05$ was considered statistically significant. All statistical analyses were performed using IBM SPSS Statistics version 26.

\section{Results}

Among the study population, moderate and severe LUTS were present in 1,317 (24.6\%) and 211 (3.9\%) men, respectively (Table 1 ). In addition to age, obesity, marital status, job, monthly income, life-long smoking amount, physical activity, and decreased HDL-cholesterol levels were significantly associated with the severity of LUTS. The presence of sleep disorders and moderate to severe stress were also significantly higher as LUTS severity increased. The PSA level and prostate volume were higher in men with severe LUTS.

Sleep disorders were significantly higher in men with severe LUTS. Although all components of sleep disorder were significantly related to the severity of LUTS, among components of sleep disorder, sleep disturbance $(r=0.322, p<0.001)$ was most closely associated with the severity of LUTS, followed by subjective sleep quality $(r=0.252, p<0.001)$, sleep latency $(r=0.184, p<0.001)$, and daytime dysfunction $(r=0.161, p<$ 0.001). In multivariate analysis, moderate and severe LUTS were significantly associated with the presence of sleep disorder, in addition to age $<50$ years, increased amount of smoking, other marital status, alcohol consumption $\geq 100 \mathrm{~g} /$ week, and decreased physical activity (Table 2). Moreover, moderate and severe LUTS were associated with moderate to severe stress, in addition to age $<50$ years, current smoking, increased amount of smoking, low income, other marital status, and decreased physical activity.

After age stratification, income was significantly associated with the presence of moderate to severe LUTS in all age groups, except for those aged $\geq 70$ years (Table 3 ). Job and current smoking status were significantly associated with moderate to severe LUTS in men aged $<60$ years. Marital status was also significantly associated with moderate to severe LUTS in men aged $<50$ and $\geq 70$ years. In contrast, MetS and its components were not significantly associated with the presence of moderate to severe LUTS after age stratification, except for decreased HDL cholesterol levels in men aged $\geq 50$ and $<60$ years. 
On multivariable analysis, older age, increased amount of life-long smoking, marital status, low income, non-office workers, and decreased HDL cholesterol levels were significantly associated with the presence of moderate to severe LUTS (Table 4). In addition, these variables were also associated with the I-PSS total score and storage sub-score in the multivariable linear regression analysis. Age, life-long smoking amount, other marital status, and low income were positively associated with voiding sub-scores, although hypertension was negatively associated with voiding sub-scores. Among metabolic components, central obesity and decreased HDL were significantly associated with prostate volume, in addition to age. In contrast, lifestyle-related variables were not associated with prostate volume (Table 5).

\section{Discussion}

QoL is becoming a more important health issue and, in elderly men, worsened BPH-induced LUTS exacerbates QoL. Moreover, medical costs for relieving LUTS tend to be significantly increased because of its impact on QoL. However, because of the close relationship between aging and BPH/LUTS, no clear strategies for preventing the development of LUTS have been developed thus far, and prevention strategies for LUTS in men are urgently needed, as mentioned previously. In the current study, we aimed to demonstrate the impact of LUTS on QoL; based on this, we thoroughly assessed the impacts of MetS and lifestyle-related factors on LUTS to suggest the effective prevention strategies for LUTS in men to improve QoL.

Based on the current study, not only severe LUTS but also moderate LUTS affect sleep quality and stress in daily life. Moreover, the presence of LUTS was the most powerful variable associated with both sleep disturbance and stress, followed by younger age and marital status. In other words, preventing the development of moderate to severe LUTS, in addition to alleviating LUTS, could be important medical issues for improving mental health and daily QoL in men. In addition, urologists need to have more interest in mental health and daily QoL, because LUTS is one of the most important factors affecting sleep disorders and stress.

In this study, the amount of life-long smoking was significantly associated with the presence of moderate and severe LUTS, which is consistent with previous studies ${ }^{15}$. However, the amount of life-long smoking was not associated with prostate volume. A previous study reported that nicotine might worsen LUTS by reducing bladder flow and urothelial hypoxia ${ }^{15}$, which supports the results of the current study. Interestingly, the impact of the amount of life-long smoking, not current smoking status ${ }^{16}$, on voiding symptoms was also observed in the current study, which supports the need for early education on the adverse effects of smoking on LUTS, although these remain to be validated in future studies. Because only a few previous studies have assessed the relationship between smoking and LUTS and these studies generally showed inconsistent results, the findings of the current study could be help clinicians and patients based on a detailed analysis of various factors related to LUTS.

In addition to age, several socioeconomic statuses, including marital status ${ }^{16}$, income, and job, showed a close relationship with the presence of moderate to severe LUTS in this study, similar to a previous study ${ }^{17}$. This might be due to the relationship between psychological stability and LUTS. In a previous study, satisfaction with life was reported to be associated with LUTS progression ${ }^{18}$, which supports these results. In addition, other lifestyle factors, such as diet and behavior, which are related to marital status, income, and job, might be the reasons for the presence of moderate to severe LUTS in men with low socioeconomic status, although these cannot be revealed in the current study. 
Among MetS and metabolic components, decreased HDL cholesterol was the only variable related to moderate to severe LUTS, which agrees with a previous study ${ }^{9}$. Moreover, the presence of decreased HDL cholesterol was associated with increased prostate volume, in addition to central obesity, which is consistent with a previous study ${ }^{19,20}$. Because the severity of LUTS is also associated with decreased HDL cholesterol, it is important to maintain an HDL-cholesterol level over $40 \mathrm{mg} / \mathrm{dL}$. Interestingly, the presence of hypertension was negatively associated with voiding symptom severity, but not with storage symptoms. These findings might be due to the effects of alleviating LUTS by angiotensin II receptor blocker medication for hypertension as described in previous studies ${ }^{21}$ although these need to be verified in future studies.

Based on the current study, alcohol consumption and exercise were not associated with the presence of moderate to severe LUTS in men aged $\geq 40$ years. In other words, the prevention of moderate to severe LUTS seemed to be achieved by life-long lifestyle modification and by maintaining a stable socioeconomic status, not by short-term daily life modification. However, because alcohol consumption and exercise were determined as factors associated with decreased sleep disorder and moderate to severe stress, the importance of appropriate alcohol consumption restriction and daily exercise to improve QoL should not be overlooked, especially in men with moderate to severe LUTS.

The current study was limited by its cross-sectional study design, although a large number of men who underwent routine health check-ups were included in the analysis. In addition, because of the study design, we could only suggest the relationship between lifestyle and MetS-related variables with the presence of moderate to severe LUTS, and the causality needs to be verified in future studies. However, to our knowledge, this is the first large study to thoroughly assess the relationship not only between LUTS and lifestyle and MetS-related variables, but also between prostate volume and lifestyle and MetS-related variables. Moreover, we assessed its impact on sleep disorders and moderate to severe stress in daily life. Therefore, this study could be useful for clinicians when counselling men, who are not only worried about or experiencing moderate to severe LUTS, but are also having sleep disorders and moderate to severe stress.

In conclusions, in men aged $\geq 40$ years, stable socioeconomic status, including married marital status, office worker, and high income, are negatively associated with the presence of moderate to severe LUTS, which worsens sleep quality and stress level. In addition, quitting smoking and maintaining HDL cholesterol levels over 40 $\mathrm{mg} / \mathrm{dL}$ might be effective lifestyle modification strategies for preventing moderate to severe LUTS. Maintaining HDL cholesterol levels, in addition to decreasing waist circumference, could also be effective in preventing prostate enlargement.

\section{Declarations}

Acknowledgements: None

\section{Author contributions:}

JB Jeong: Data collection, Manuscript writing, Data analysis

JH Lee: Data collection

MS Choo: Data analysis 
D-W Ahn: Data collection

SH Kim: Data collection

DS Lee: Data collection

MC Cho: Manuscript revision

H Son: Study design/concept

H Jeong: Study design/concept

S Yoo: Study design/concept, Data analysis, Manuscript writing, Manuscript revision

Additional information: None

\section{References}

1. Robertson, C. et al. The impact of lower urinary tract symptoms and comorbidities on quality of life: the BACH and UREPIK studies. 99,347-354(2007).

2. Coyne, K. S. et al. The burden of lower urinary tract symptoms: evaluating the effect of LUTS on healthrelated quality of life, anxiety and depression: EpiLUTS. 103,4-11(2009).

3. Irwin, D. E., Kopp, Z. S., Agatep, B., Milsom, I. \& Abrams, P. J. B. i. Worldwide prevalence estimates of lower urinary tract symptoms, overactive bladder. urinary incontinence and bladder outlet obstruction, 108, 11321138 (2011).

4. Van Exel, N. et al. Medical consumption and costs during a one-year follow-up of patients with LUTS suggestive of BPH in six European countries: report of the TRIUMPH study. 49,92-102(2006).

5. Ford, E. S. J. D. c. Risks for all-cause mortality, cardiovascular disease, and diabetes associated with the metabolic syndrome: a summary of the evidence. 28,1769-1778(2005).

6. Vanhanen, M. et al. Association of metabolic syndrome with Alzheimer disease: a population-based study. 67,843-847(2006).

7. Cowey, S. \& Hardy, R. W. J. T. A. j. o. p. The metabolic syndrome: a high-risk state for cancer? 169,15051522(2006).

8. Li, J. et al. The association between metabolic syndrome and benign prostatic hyperplasia: a systematic review and meta-analysis.1-12(2020).

9. Yoo, S. et al. The impacts of metabolic syndrome and lifestyle on the prevalence of benign prostatic hyperplasia requiring treatment: historical cohort study of 130454 men. 123,140-148(2019).

10. Yoo, S. et al. Effects of metabolic syndrome on the prevalence of prostate cancer: historical cohort study using the national health insurance service database. 145,775-780(2019).

11. Pashootan, P., Ploussard, G., Cocaul, A., de Gouvello, A. \& Desgrandchamps, F. J. B. i. Association between metabolic syndrome and severity of lower urinary tract symptoms (LUTS): an observational study in a 4666 E uropean men cohort. 116,124-130(2015).

12. Kupelian, V. et al. Association of lower urinary tract symptoms and the metabolic syndrome: results from the Boston. Area Community Health Survey, 182, 616-625 (2009). 
13. Park, H. K. et al. Relationship between lower urinary tract symptoms and metabolic syndrome in a community-based elderly population. 72,556-560(2008).

14. Gao, Y. et al. Are metabolic syndrome and its components associated with lower urinary tract symptoms? Results from a Chinese male population survey. 79,194-201(2012).

15. Nagai, T. et al. Nicotine-induced hypoxia in rat urothelium deteriorates bladder storage functions. Neurourology and urodynamics, 38, 1560-1570 https://doi.org/10.1002/nau.24050 (2019).

16. Bradley, C. S. et al. Evidence of the Impact of Diet, Fluid Intake, Caffeine, Alcohol and Tobacco on Lower Urinary Tract Symptoms: A Systematic Review. The Journal of urology, 198, 1010-1020 https://doi.org/10.1016/j.juro.2017.04.097 (2017).

17. Fowke, J. H., Munro, H., Signorello, L. B., Blot, W. J. \& Penson, D. F. J. J. o. g. i. m. Association between socioeconomic status (SES) and lower urinary tract symptom (LUTS) severity among black and white men. 26,1305-1310(2011).

18. Rohrmann, S., Katzke, V. A. \& Kaaks, R. J. U. Lifestyle and Progression of Lower Urinary Tract Symptoms in German Men-Results From the EPIC-Heidelberg Cohort. 120,192-196(2018).

19. Gacci, M. et al. Metabolic syndrome and benign prostatic enlargement: a systematic review and metaanalysis. 115,24-31(2015).

20. Lee, R. K., Chung, D., Chughtai, B., Te, A. E. \& Kaplan, S. A. J. B. i. Central obesity as measured by waist circumference is predictive of severity of lower urinary tract symptoms. 110,540-545(2012).

21. Ito, H. et al. IPSS is lower in hypertensive patients treated with angiotensin-II receptor blocker: posthoc analyses of a lower urinary tract symptoms population. 32,70-74(2013).

22. Choi, H. R. et al. Translation validity and reliability of I-PSS Korean version. 37,659-665(1996).

23. Sohn, S. I., Kim, D. H., Lee, M. Y. \& Cho, Y. W. J. S. \& Breathing. The reliability and validity of the Korean version of the Pittsburgh Sleep Quality Index, 16, 803-812 (2012).

24. Kim, K. N. et al. Degree of stress and stress-related factors by the Korean version of the BEPSI. 19,559570(1998).

25. Expert Panel on Detection, E. J. J. Executive summary of the third report of the National Cholesterol Education Program (NCEP) expert panel on detection, evaluation, and treatment of high blood cholesterol in adults (Adult Treatment Panel III). 285,2486-2497(2001).

26. Smyth, C. (SLACK Incorporated Thorofare, NJ, 1999).

27. Frank, S. H. \& Zyzanski, S. J. J. T. J. o. f. p. Psychosocial instrument, 26, 533-539 (1988).

28. Lee, S. P. et al. The effect of emotional stress and depression on the prevalence of digestive diseases. 21,273(2015).

\section{Tables}

Table 1. Baseline characteristics according to severity of LUTS 


\begin{tabular}{|c|c|c|c|c|}
\hline & None to mild & Moderate & Severe & $\mathrm{P}$ \\
\hline N (\%) & 3827 (71.5) & $1317(24.6)$ & $211(3.9)$ & \\
\hline Age, years, mean $\pm S D$ & $52.4 \pm 8.8$ & $56.5 \pm 9.4$ & $59.0 \pm 9.7$ & $<0.001$ \\
\hline Body weight, kg, mean \pm SD & $72.4 \pm 10.4$ & $70.7 \pm 9.9$ & $69.3 \pm 10.4$ & $<0.001$ \\
\hline $\mathrm{BMI}, \mathrm{kg} / \mathrm{m}^{2}$, mean $\pm \mathrm{SD}$ & $24.7 \pm 2.9$ & $24.4 \pm 2.9$ & $24.2 \pm 3.1$ & $<0.001$ \\
\hline Waist circumference, $\mathrm{cm}$, mean \pm SD & $87.1 \pm 8.2$ & $87.0 \pm 8.1$ & $87.3 \pm 8.6$ & 0.858 \\
\hline Marital status, n (\%) & & & & $<0.001$ \\
\hline Yes & $3449(90.1)$ & $1161(88.2)$ & $164(77.7)$ & \\
\hline Others & $354(9.3)$ & $140(10.6)$ & $44(20.9)$ & \\
\hline Unknown & $24(0.6)$ & $16(1.2)$ & $3(1.4)$ & \\
\hline Job, n (\%) & & & & $<0.001$ \\
\hline Office-worker & $2678(70.0)$ & $752(57.1)$ & $90(42.7)$ & \\
\hline Others & $1028(26.9)$ & $504(38.3)$ & $103(48.8)$ & \\
\hline Unknown & $121(2.3)$ & $61(4.6)$ & $18(8.5)$ & \\
\hline Monthly income, n (\%) & & & & $<0.001$ \\
\hline$<\$ 2684$ & $3221(84.2)$ & $985(74.8)$ & $127(60.2)$ & \\
\hline$\geq \$ 2684$ & $455(11.9)$ & $250(19.0)$ & $67(31.8)$ & \\
\hline Unknown & $151(3.9)$ & $82(6.2)$ & $17(8.1)$ & \\
\hline Current smoker, n (\%) & $1169(30.5)$ & $380(28.9)$ & $68(32.2)$ & 0.414 \\
\hline Amount of smoking, $P Y$, mean \pm SD & $11.6 \pm 13.7$ & $14.8 \pm 16.7$ & $19.0 \pm 19.5$ & $<0.001$ \\
\hline Drinking, g/week, mean \pm SD & & & & 0.310 \\
\hline $0 \mathrm{~g} /$ week & $997(26.1)$ & $354(26.9)$ & $60(28.4)$ & \\
\hline$>0$ and $<100 \mathrm{~g} /$ week & $875(22.9)$ & $291(22.1)$ & $43(20.4)$ & \\
\hline$\geq 100 \mathrm{~g} /$ week & $1876(49.0)$ & $649(49.3)$ & $99(46.9)$ & \\
\hline Unknown & $79(2.1)$ & $23(1.7)$ & $9(4.3)$ & \\
\hline In $(\mathrm{MET})$, mean $\pm \mathrm{SD}$ & $5.6 \pm 3.0$ & $5.6 \pm 3.0$ & $3.0 \pm 5.0$ & 0.015 \\
\hline Metabolic syndrome, n (\%) & 1395 (36.5) & $516(39.2)$ & $85(40.3)$ & 0.137 \\
\hline Central obesity, n (\%) & $1419(37.1)$ & $468(35.5)$ & $80(37.9)$ & 0.567 \\
\hline Hypertension, n (\%) & 2355 (61.5) & $800(60.7)$ & $132(62.6)$ & 0.824 \\
\hline Diabetes, n (\%) & $1370(35.8)$ & $502(38.1)$ & $90(42.7)$ & 0.058 \\
\hline Triglyceridemia, n (\%) & $1521(39.7)$ & $567(43.1)$ & $86(40.8)$ & 0.108 \\
\hline
\end{tabular}




\begin{tabular}{lllll} 
Decreased HDL, n (\%) & $1126(29.4)$ & $476(36.1)$ & $69(32.7)$ & $<0.001$ \\
\hline Sleep disorder, n (\%) & $1725(45.4)$ & $802(61.6)$ & $154(74.4)$ & $<0.001$ \\
\hline Stress, n (\%) & $1160(30.3)$ & $541(41.1)$ & $115(54.5)$ & $<0.001$ \\
\hline PSA, mL, mean \pm SD & $1.56 \pm 1.58$ & $1.92 \pm 5.11$ & $2.59 \pm 4.41$ & $<0.001$ \\
\hline Prostate size, cc, mean \pm SD (n=827) & $25.2 \pm 7.8$ & $25.5 \pm 7.8$ & $28.9 \pm 13.1$ & 0.001
\end{tabular}

Table 2. Variables associated with quality of life

(a) Variables associated with the presence of sleep disorder 


\begin{tabular}{|c|c|c|c|c|}
\hline & Univariate & & Multivariable & \\
\hline & OR $(95 \% \mathrm{Cl})$ & $P$ & OR $(95 \% \mathrm{Cl})$ & $P$ \\
\hline \multicolumn{5}{|l|}{ Age group } \\
\hline$\geq 40$ and $<50$ & Reference & & Reference & \\
\hline$\geq 50$ and $<60$ & $0.806(0.711-0.913)$ & 0.001 & $0.719(0.631-0.820)$ & $<0.001$ \\
\hline$\geq 60$ and $<70$ & $0.790(0.679-0.918)$ & 0.002 & $0.632(0.534-0.747)$ & $<0.001$ \\
\hline$\geq 70$ & $0.897(0.707-1.137)$ & 0.368 & $0.664(0.510-0.866)$ & 0.003 \\
\hline Current smoker (yes vs. no) & $1.412(1.255-1.589)$ & $<0.001$ & & \\
\hline Amount of smoking (continuous) & $1.013(1.009-1.017)$ & $<0.001$ & $1.010(1.006-1.014)$ & $<0.001$ \\
\hline \multicolumn{5}{|l|}{ Marital status, n (\%) } \\
\hline Yes & Reference & & Reference & \\
\hline Others & $1.917(1.591-2.309)$ & $<0.001$ & $1.665(1.371-2.023)$ & $<0.001$ \\
\hline Unknown & $1.323(0.723-2.421)$ & 0.365 & $0.921(0.477-1.779)$ & 0.806 \\
\hline \multicolumn{5}{|l|}{ Income } \\
\hline$\geq \$ 2684$ & Reference & & & \\
\hline$<\$ 2684$ & $1.186(1.016-1.384)$ & 0.031 & & \\
\hline Unknown & $1.265(0.977-1.637)$ & 0.074 & & \\
\hline \multicolumn{5}{|l|}{ Job, n (\%) } \\
\hline Office-worker & Reference & & Reference & \\
\hline Others & $1.150(1.022-1.294)$ & 0.021 & $1.043(0.913-1.193)$ & 0.534 \\
\hline Unknown & $1.664(1.242-2.230)$ & 0.001 & $1.560(1.127-2.160)$ & 0.007 \\
\hline \multicolumn{5}{|l|}{ Alcohol consumption, $\mathrm{n}(\%)$} \\
\hline $0 \mathrm{~g} /$ week & Reference & & Reference & \\
\hline$>0$ and $<100 \mathrm{~g} /$ week & $0.933(0.799-1.089)$ & 0.376 & $0.965(0.823-1.132)$ & 0.661 \\
\hline$\geq 100 \mathrm{~g} /$ week & $1.358(1.192-1.547)$ & $<0.001$ & $1.288(1.123-1.477)$ & $<0.001$ \\
\hline Unknown & $0.895(0.603-1.326)$ & 0.580 & $0.875(0.583-1.313)$ & 0.518 \\
\hline MET, In (continuous) & $0.976(0.958-0.993)$ & 0.007 & $0.979(0.961-.0998)$ & 0.029 \\
\hline Metabolic syndrome (yes vs. no) & $1.093(0.973-1.229)$ & 0.134 & & \\
\hline \multicolumn{5}{|l|}{ IPSS severity } \\
\hline Normal to mild & Reference & & Reference & \\
\hline Moderate & $1.603(1.408-1.825)$ & $<0.001$ & $2.012(1.761-2.300)$ & $<0.001$ \\
\hline
\end{tabular}


(b) Variables associated with the presence of moderate to severe stress 


\begin{tabular}{|c|c|c|c|c|}
\hline & Univariate & & Multivariable & \\
\hline & OR $(95 \% \mathrm{Cl})$ & $P$ & OR $(95 \% \mathrm{Cl})$ & $P$ \\
\hline \multicolumn{5}{|l|}{ Age group } \\
\hline$\geq 40$ and $<50$ & Reference & & Reference & \\
\hline$\geq 50$ and $<60$ & $0.624(0.548-0.710)$ & $<0.001$ & $0.570(0.497-0.655)$ & $<0.001$ \\
\hline$\geq 60$ and $<70$ & $0.502(0.426-0.591)$ & $<0.001$ & $0.401(0.334-0.482)$ & $<0.001$ \\
\hline$\geq 70$ & $0.506(0.389-0.658)$ & $<0.001$ & $0.365(2.302-4.161)$ & $<0.001$ \\
\hline Current smoker (yes vs. no) & $1.753(1.554-1.978)$ & $<0.001$ & $1.388(1.208-1.596)$ & $<0.001$ \\
\hline Amount of smoking (continuous) & $1.010(1.006-1.014)$ & $<0.001$ & $1.006(1.002-1.011)$ & 0.004 \\
\hline \multicolumn{5}{|l|}{ Marital status, n (\%) } \\
\hline Yes & Reference & & Reference & \\
\hline Others & $2.170(1.813-2.597)$ & $<0.001$ & $1.696(1.397-2.059)$ & $<0.001$ \\
\hline Unknown & $1.137(0.605-2.135)$ & 0.690 & $1.093(0.793-1.439)$ & 0.665 \\
\hline \multicolumn{5}{|l|}{ Income } \\
\hline$\geq \$ 2684$ & Reference & & Reference & \\
\hline$<\$ 2684$ & $1.324(1.131-1.550)$ & $<0.001$ & $1.286(1.072-1.542)$ & 0.007 \\
\hline Unknown & $1.069(0.817-1.398)$ & 0.626 & $1.093(0.555-2.152)$ & 0.798 \\
\hline \multicolumn{5}{|l|}{ Job, n (\%) } \\
\hline Office-worker & Reference & & & \\
\hline Others & $1.081(0.955-1.223)$ & 0.219 & & \\
\hline Unknown & $1.346(1.006-1.801)$ & 0.046 & & \\
\hline \multicolumn{5}{|l|}{ Alcohol consumption, $\mathrm{n}(\%)$} \\
\hline $0 \mathrm{~g} /$ week & Reference & & & \\
\hline$>0$ and $<100 \mathrm{~g} /$ week & $0.992(0.841-1.171)$ & 0.927 & & \\
\hline$\geq 100 \mathrm{~g} /$ week & $1.298(1.131-1.490)$ & $<0.001$ & & \\
\hline Unknown & $0.780(0.504-1.210)$ & 0.268 & & \\
\hline MET, In (continuous) & $0.978(0.960-0.997)$ & 0.021 & $0.980(0.961-1.000)$ & 0.046 \\
\hline Metabolic syndrome (yes vs. no) & $1.093(0.973-1.229)$ & 0.134 & & \\
\hline \multicolumn{5}{|l|}{ IPSS severity } \\
\hline Normal to mild & Reference & & Reference & \\
\hline Moderate & $1.603(1.408-1.825)$ & $<0.001$ & $1.844(1.607-2.115)$ & $<0.001$ \\
\hline
\end{tabular}


Table 3. The presence of moderate to severe LUTS according to age group, life-style related variables and metabolic components

(a) The presence of moderate to severe LUTS according to age group and life-style related variables

\begin{tabular}{|c|c|c|c|c|c|}
\hline & & $\geq 40$ and $<50$ & $\geq 50$ and $<60$ & $\geq 60$ and $<70$ & $\geq 70$ \\
\hline \multirow[t]{4}{*}{ Income } & $\geq \$ 2684$ & $314(17.4)$ & 479 (28.2) & $250(36.3)$ & $69(46.3)$ \\
\hline & $<\$ 2684$ & $42(30.7)$ & 77 (35.2) & $131(44.7)$ & $67(54.5)$ \\
\hline & unknown & $14(25.5)$ & $28(35.4)$ & $30(45.5)$ & $27(54.0)$ \\
\hline & $\mathrm{P}$ & $<0.001$ & 0.050 & 0.028 & 0.356 \\
\hline \multirow[t]{4}{*}{ Marital status } & Marriage & 305 (17.7) & $522(28.6)$ & 361 (38.3) & $137(48.9)$ \\
\hline & Others & $62(24.6)$ & 59 (36.4) & $43(48.3)$ & $20(57.1)$ \\
\hline & unknown & $3(23.1)$ & $3(37.5)$ & $7(46.7)$ & $6(85.7)$ \\
\hline & $\mathrm{P}$ & 0.028 & 0.099 & 0.151 & 0.001 \\
\hline \multirow[t]{4}{*}{ Job } & Office worker & $264(16.4)$ & $379(27.3)$ & $166(36.2)$ & $33(51.6)$ \\
\hline & Others & $96(28.1)$ & $179(33.0)$ & $223(41.4)$ & $103(51.4-$ \\
\hline & unknown & $10(25.6)$ & $26(40.0)$ & $22(44.0)$ & $21(45.7)$ \\
\hline & $\mathrm{P}$ & $<0.001$ & 0.008 & .183 & 0.767 \\
\hline \multirow[t]{3}{*}{ Current smoking } & No & $210(17.1)$ & $393(28.0)$ & $334(40.1)$ & $143(52.4)$ \\
\hline & Yes & $160(20.9)$ & $191(32.5)$ & $77(35.8)$ & $20(40.8)$ \\
\hline & $\mathrm{P}$ & 0.034 & 0.043 & 0.246 & 0.136 \\
\hline \multirow[t]{5}{*}{ Alcohol consumption } & $0 \mathrm{~g} /$ week & $72(16.9)$ & 151 (29.7) & 119 (36.2) & $72(49.0)$ \\
\hline & $<100 \mathrm{~g} / \mathrm{wk}$ & $81(18.0)$ & 125 (28.5) & $86(35.8)$ & $42(52.5)$ \\
\hline & $\geq 100 \mathrm{~g} / \mathrm{wk}$ & 214 (19.7) & 300 (29.6) & $192(43.1)$ & $42(51.9)$ \\
\hline & Unknown & $3(9.7)$ & $8(24.2)$ & $14(42.4)$ & $7(50.0)$ \\
\hline & $\mathrm{P}$ & 0.326 & 0.889 & 0.141 & 0.956 \\
\hline
\end{tabular}

(b) The presence of moderate to severe LUTS according to age group and metabolic syndrome / metabolic components 


\begin{tabular}{|c|c|c|c|c|c|}
\hline & & $\geq 40$ and $<50$ & $\geq 50$ and $<60$ & $\geq 60$ and $<70$ & $\geq 70$ \\
\hline \multirow[t]{3}{*}{ Metabolic syndrome } & Yes & 125 (18.8) & $230(30.3)$ & $173(40.3)$ & $73(51.0)$ \\
\hline & No & 245 (18.5) & 354 (28.7) & $238(38.5)$ & $90(5.3)$ \\
\hline & $P$ & 0.856 & 0.435 & 0.554 & 0.891 \\
\hline \multirow[t]{3}{*}{ Central obesity } & Yes & 134 (17.3) & $201(29.2)$ & $154(41.0)$ & $59(46.1)$ \\
\hline & No & 236 (19.4) & 383 (29.3) & 257 (38.3) & $104(53.6)$ \\
\hline & $\mathrm{p}$ & 0.240 & 0.959 & 0.398 & 0.187 \\
\hline \multirow[t]{3}{*}{ Hypertension } & Yes & $208(18.4)$ & $342(28.1)$ & $281(38.8)$ & $101(47.9)$ \\
\hline & No & 162 (18.9) & 242 (31.2) & $130(40.2)$ & $49(44.1)$ \\
\hline & $\mathrm{p}$ & 0.776 & 0.129 & 0.660 & 0.173 \\
\hline \multirow[t]{3}{*}{ Diabetes } & Yes & $103(18.5)$ & $225(28.7)$ & $191(40.4)$ & $73(49.0)$ \\
\hline & No & $267(18.6)$ & $359(29.7)$ & $220(38.3)$ & $90(52.0)$ \\
\hline & $\mathrm{P}$ & 0.972 & 0.642 & 0.498 & 0.588 \\
\hline \multirow[t]{3}{*}{ Triglyceridemia } & Yes & $163(19.8)$ & $261(31.3)$ & $163(40.4)$ & $66(56.9)$ \\
\hline & No & 207 (17.7) & 323 (27.8) & $248(38.5)$ & $97(47.1)$ \\
\hline & $P$ & 0.227 & .0089 & 0.532 & 0.091 \\
\hline \multirow[t]{3}{*}{ Decreased HDL } & Yes & $101(20.0)$ & $210(32.3)$ & $159(41.6)$ & $75(56.0)$ \\
\hline & No & $269(18.1)$ & $374(27.8)$ & $252(37.9)$ & $88(46.8)$ \\
\hline & $P$ & 0.340 & 0.039 & 0.234 & 0.105 \\
\hline
\end{tabular}

Table 4. Variables associated with the severity of LUTS 


\begin{tabular}{|c|c|c|c|c|c|c|c|c|}
\hline & \multicolumn{4}{|c|}{ Moderate to severe LUTS } & \multicolumn{4}{|c|}{ Severe LUTS } \\
\hline & \multicolumn{2}{|l|}{ Univariate } & \multicolumn{2}{|c|}{ Multivariable } & \multicolumn{2}{|l|}{ Univariate } & \multicolumn{2}{|c|}{ Multivariable } \\
\hline & $\begin{array}{l}\mathrm{OR}(95 \% \\
\mathrm{Cl})\end{array}$ & $P$ & $\begin{array}{l}\mathrm{OR}(95 \% \\
\mathrm{Cl})\end{array}$ & $\mathrm{P}$ & $\begin{array}{l}\text { OR }(95 \% \\
\mathrm{Cl})\end{array}$ & $P$ & $\begin{array}{l}\mathrm{OR}(95 \% \\
\mathrm{Cl})\end{array}$ & $P$ \\
\hline \multicolumn{9}{|l|}{ Age group } \\
\hline$\geq 40$ and $<50$ & Reference & & Reference & & Reference & & Reference & \\
\hline$\geq 50$ and $<60$ & $\begin{array}{l}1.816 \\
(1.565- \\
2.106)\end{array}$ & $<0.001$ & $\begin{array}{l}1.676 \\
(1.440- \\
1.952)\end{array}$ & $<0.001$ & $\begin{array}{l}1.723 \\
(1.160- \\
2.559)\end{array}$ & 0.007 & $\begin{array}{l}1.602 \\
(1.072- \\
2.395)\end{array}$ & 0.022 \\
\hline$\geq 60$ and $<70$ & $\begin{array}{l}2.833 \\
(2.395- \\
3.350)\end{array}$ & $<0.001$ & $\begin{array}{l}2.299 \\
(1.920- \\
2.754)\end{array}$ & $<0.001$ & $\begin{array}{l}3.604 \\
(2.430- \\
5.344)\end{array}$ & $<0.001$ & $\begin{array}{l}2.843 \\
(1.873- \\
4.313)\end{array}$ & $<0.001$ \\
\hline$\geq 70$ & $\begin{array}{l}4.494 \\
(3.514- \\
5.747)\end{array}$ & $<0.001$ & $\begin{array}{l}3.414 \\
(2.618- \\
4.452)\end{array}$ & $<0.001$ & $\begin{array}{l}5.199 \\
(3.201- \\
8.443)\end{array}$ & $<0.001$ & $\begin{array}{l}3.864 \\
(2.307- \\
6.472)\end{array}$ & $<0.001$ \\
\hline $\begin{array}{l}\text { Current } \\
\text { smoker }\end{array}$ & $\begin{array}{l}0.943 \\
(0.828- \\
1.074)\end{array}$ & 0.377 & & & $\begin{array}{l}1.104 \\
(0.822- \\
1.482)\end{array}$ & 0.512 & & \\
\hline $\begin{array}{l}\text { Amount of } \\
\text { smoking }\end{array}$ & $\begin{array}{l}1.017 \\
(1.013- \\
1.021)\end{array}$ & $<0.001$ & $\begin{array}{l}1.011 \\
(1.007- \\
1.015)\end{array}$ & $<0.001$ & $\begin{array}{l}1.023 \\
(1.016- \\
1.030)\end{array}$ & $<0.001$ & $\begin{array}{l}1.017 \\
(1.432- \\
3.034)\end{array}$ & $<0.001$ \\
\hline \multicolumn{9}{|l|}{$\begin{array}{l}\text { Marital status, } \\
\mathrm{n}(\%)\end{array}$} \\
\hline Yes & Reference & & Reference & & Reference & & Reference & \\
\hline Others & $\begin{array}{l}1.353 \\
(1.120- \\
1.635)\end{array}$ & 0.002 & $\begin{array}{l}1.238 \\
(1.007- \\
1.522)\end{array}$ & 0.043 & $\begin{array}{l}2.504 \\
(1.772- \\
3.537)\end{array}$ & $<0.001$ & $\begin{array}{l}2.084 \\
(1.432- \\
3.034)\end{array}$ & $<0.001$ \\
\hline Unknown & $\begin{array}{l}2.061 \\
(1.125- \\
3.774)\end{array}$ & 0.019 & $\begin{array}{l}1.435 \\
(0.735- \\
2.807)\end{array}$ & 0.291 & $\begin{array}{l}2.108 \\
(0.646- \\
6.885)\end{array}$ & 0.217 & $\begin{array}{l}1.324 \\
(0.374- \\
4.688)\end{array}$ & 0.663 \\
\hline \multicolumn{9}{|l|}{ Income } \\
\hline$\geq \$ 2684$ & Reference & & Reference & & Reference & & Reference & \\
\hline$<\$ 2684$ & $\begin{array}{l}2.018 \\
(1.722- \\
2.365)\end{array}$ & $<0.001$ & $\begin{array}{l}1.251 \\
(1.036- \\
1.510)\end{array}$ & 0.020 & $\begin{array}{l}3.147 \\
(2.317- \\
4.276)\end{array}$ & $<0.001$ & $\begin{array}{l}1.775 \\
(1.258- \\
2.503)\end{array}$ & 0.001 \\
\hline Unknown & $\begin{array}{l}1.899 \\
(1.461- \\
2.649)\end{array}$ & $<0.001$ & $\begin{array}{l}1.282 \\
(0.942- \\
1.744)\end{array}$ & 0.113 & $\begin{array}{l}2.416 \\
(1.432- \\
4.077)\end{array}$ & 0.001 & $\begin{array}{l}1.528 \\
(0.861- \\
2.711)\end{array}$ & 0.148 \\
\hline \multicolumn{9}{|l|}{ Job, n (\%) } \\
\hline Office-worker & Reference & & Reference & & Reference & & & \\
\hline Others & $\begin{array}{l}1.878 \\
(1.654- \\
2.132)\end{array}$ & $<0.001$ & $\begin{array}{l}1.234 \\
(1.061- \\
1.435)\end{array}$ & 0.006 & $\begin{array}{l}2.562 \\
(1.919- \\
3.421)\end{array}$ & $<0.001$ & & \\
\hline
\end{tabular}




\begin{tabular}{|c|c|c|c|c|c|c|}
\hline Unknown & $\begin{array}{l}2.077 \\
(1.548- \\
2.786)\end{array}$ & $<0.001$ & $\begin{array}{l}1.168 \\
(0.824- \\
1.657)\end{array}$ & 0.382 & $\begin{array}{l}3.769 \\
(2.224- \\
6.388)\end{array}$ & $<0.001$ \\
\hline \multicolumn{7}{|l|}{$\begin{array}{l}\text { Alcohol } \\
\text { consumption, } \\
\text { n (\%) }\end{array}$} \\
\hline $0 \mathrm{~g} /$ week & Reference & & & & Reference & \\
\hline $\begin{array}{l}>0 \text { and }<100 \\
\text { g/week }\end{array}$ & $\begin{array}{l}0.919 \\
(0.775- \\
1.090)\end{array}$ & 0.333 & & & $\begin{array}{l}0.830 \\
(0.557- \\
1.238)\end{array}$ & 0.362 \\
\hline$\geq 100 \mathrm{~g} /$ week & $\begin{array}{l}0.960 \\
(0.833- \\
1.107)\end{array}$ & 0.577 & & & $\begin{array}{l}0.883 \\
(0.636- \\
1.225)\end{array}$ & 0.456 \\
\hline Unknown & $\begin{array}{l}0.975 \\
(0.637- \\
1.494)\end{array}$ & 0.909 & & & $\begin{array}{l}1.987 \\
(.0958- \\
4.118)\end{array}$ & 0.065 \\
\hline $\begin{array}{l}\text { MET, In } \\
\text { (continuous) }\end{array}$ & $\begin{array}{l}0.992 \\
(.973- \\
1.012)\end{array}$ & 0.425 & & & $\begin{array}{l}0.940 \\
(0.901- \\
0.981)\end{array}$ & 0.004 \\
\hline $\begin{array}{l}\text { Metabolic } \\
\text { syndrome }\end{array}$ & $\begin{array}{l}1.130 \\
(1.001- \\
1.277)\end{array}$ & 0.049 & & & $\begin{array}{l}1.141 \\
(0.862- \\
1.511)\end{array}$ & 0.356 \\
\hline Central obesity & $\begin{array}{l}0.949 \\
(0.839- \\
1.074)\end{array}$ & 0.405 & & & $\begin{array}{l}1.054 \\
(0.794- \\
1.400)\end{array}$ & 0.716 \\
\hline Hypertension & $\begin{array}{l}0.977 \\
(0.865- \\
1.104)\end{array}$ & 0.713 & & & $\begin{array}{l}1.053 \\
(0.793- \\
1.400)\end{array}$ & 0.720 \\
\hline Diabetes & $\begin{array}{l}1.134 \\
(1.004- \\
1.282)\end{array}$ & 0.043 & & & $\begin{array}{l}1.300 \\
(0.984- \\
1.718)\end{array}$ & 0.065 \\
\hline Triglyceridemia & $\begin{array}{l}1.131 \\
(1.003- \\
1.276)\end{array}$ & 0.044 & & & $\begin{array}{l}1.007 \\
(0.761- \\
1.333)\end{array}$ & 0.961 \\
\hline $\begin{array}{l}\text { Decreased } \\
\text { HDL }\end{array}$ & $\begin{array}{l}1.330 \\
(1.173- \\
1.508)\end{array}$ & $<0.001$ & $\begin{array}{l}1.191 \\
(1.045- \\
1.357)\end{array}$ & 0.009 & $\begin{array}{l}1.074 \\
(0.801- \\
1.441)\end{array}$ & 0.632 \\
\hline
\end{tabular}

Table 5. Variables associated prostate volume 


\begin{tabular}{|c|c|c|c|c|}
\hline & \multicolumn{4}{|c|}{ Prostate volume } \\
\hline & \multicolumn{2}{|c|}{ Univariate } & \multicolumn{2}{|l|}{ Multivariable } \\
\hline & $\mathrm{B}$ & $P$ & OR $(95 \% \mathrm{Cl})$ & $\mathrm{P}$ \\
\hline Age & 0.200 & $<0.001$ & $0.193(0.125-0.260)$ & $<0.001$ \\
\hline Current smoker & -1.018 & 0.138 & & \\
\hline Amount of smoking & -0.024 & 0.219 & & \\
\hline Marriage & -0.847 & 0.399 & & \\
\hline Low income & 0.785 & 0.284 & & \\
\hline Non office-worker & 1.004 & 0.107 & & \\
\hline Alcohol consumption, n (\%) & -0.001 & 0.612 & & \\
\hline MET, In (continuous) & -0.051 & 0.609 & & \\
\hline Metabolic syndrome & 1.140 & 0.064 & & \\
\hline Central obesity & 1.516 & 0.014 & $1.249(0.040-2.459)$ & 0.043 \\
\hline Hypertension & 1.690 & 0.005 & & \\
\hline Diabetes & -0.069 & 0.911 & & \\
\hline Triglyceridemia & 0.237 & 0.699 & & \\
\hline Decreased HDL & 1.849 & 0.004 & $1.262(0.006-2.518)$ & 0.049 \\
\hline
\end{tabular}

